$$
\text { Pontifícia Universidade C Católica }
$$

Rafael Brettas Sesto

\begin{abstract}
Análise de métodos para Seleção de Transportadores: um estudo de caso na América Central
\end{abstract}

Dissertação de Mestrado

Dissertação apresentada como requisito parcial para obtenção do grau de Mestre (opção profissional) pelo Programa de Pós-Graduação em Engenharia de Produção do Departamento de Engenharia Industrial da PUC-Rio.

Orientador: Prof. José Eugenio Leal

Rio de Janeiro

Setembro de 2009 


$$
\text { Pontifícia Universidade C Católica }
$$

Rafael Brettas Sesto

\title{
Análise de métodos para Seleção de Transportadores: um estudo de caso na América Central
}

Dissertação apresentada, como requisito parcial para obtenção do título de Mestre (opção profissional) pelo Programa de Pós-Graduação em Engenharia de Produção do Departamento de Engenharia Industrial da PUC-Rio. Aprovada pela Comissão Examinadora abaixo assinada.

\author{
Prof. José Eugenio Leal \\ Orientador \\ Departamento de Engenharia Industrial - PUC-Rio
}

Prof. Marcio Almeida D’Agosto

COPPE - UFRJ

Prof. Ronaldo Balassiano

COPPE - UFRJ

Prof. José Eugenio Leal

Coordenador Setorial do Centro Técnico Científico - PUC-Rio

Rio de Janeiro, 02 de setembro de 2009 
Todos os direitos reservados. É proibida a reprodução total ou parcial do trabalho sem autorização da universidade, do autor e do orientador.

\section{Rafael Brettas Sesto}

Graduou-se em Administração de Empresas pela PUC-Rio em 2001. Atua, desde 1999, na área de logística e transporte de empresas multinacionais. Atualmente é Gerente de Segurança em Transporte para a América Central e República Dominicana de uma empresa da área de Petróleo.

Ficha Catalográfica

Sesto, Rafael Brettas

Análise de métodos para seleção de transportadores : um estudo de caso na América Central / Rafael Brettas Sesto ; orientador: José Eugenio Leal. 2009.

$91 \mathrm{f} . ; 30 \mathrm{~cm}$

Dissertação (Mestrado em Engenharia Industrial) Pontifícia Universidade Católica do Rio de Janeiro, Rio de Janeiro, 2009.

Inclui bibliografia

1. Engenharia industrial - Teses. 2. Terceirização de Transporte. 3. Seleção de transportador. 4. Decisão multicriterial. II. Leal, José Eugenio. II. Pontifícia Universidade Católica do Rio de Janeiro. Departamento de Engenharia Industrial. III. Título. 


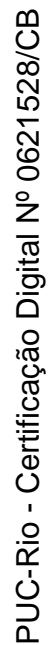

À minha esposa, Carmina, farol que ilumina o porto seguro nas noites de tempestade. 


\section{Agradecimentos}

Ao meu orientador, Professor José Eugenio Leal, pelas incríveis idéias, paciência infinita e suporte que me brindou dentro e fora do Brasil.

Ao meu pai, Justo, que financiou este curso nos momentos mais complicados.

À minha mãe, Isabel, que ajudou na revisão do texto. 


\section{Resumo}

Sesto, Rafael Brettas; Leal, José Eugenio (Orientador). A aplicação do método AHP simplificado em uma redução maciça de transportadores, um estudo de caso na América Central. Rio de Janeiro, 2009. 91p. Dissertação de Mestrado (Opção profissional) Departamento de Engenharia Industrial, Pontifícia Universidade Católica do Rio de Janeiro.

Nas últimas décadas, foi possível presenciar a forte pressão da opinião pública para reduzir os acidentes com danos ambientais e colisões rodoviárias. Diversas empresas multinacionais, organizações não-governamentais, assim como governos têm investido muitos recursos nesse sentido. A Alfa, uma empresa petroleira com grande presença na América Central, fez uma enorme redução de empresas fornecedoras de transporte nesta região para poder gerenciar, de maneira mais adequada, seus contratados e, junto com eles, trabalhar em busca da minimização do número de acidentes. Assim, no lapso de três anos, a empresa cortou suas relações com quase uma centena de fornecedores e reestruturou sua operação de transporte contratado. Para chegar a um número tão menor de provedores, a empresa lançou mão de várias técnicas de análise de fornecedores de transporte, de técnicas de negociação eletrônica pela Internet e de um método multicritério de apoio à decisão, desenvolvido por ela. Cada uma destas etapas foi revista à luz da bibliografia acadêmica correspondente, o que possibilita a comparação de modelos apontados somente na teoria quanto à sua aplicação prática. Os resultados mostraram que o caso estudado, além de haver conseguido chegar a seu objetivo, é um caso de sucesso que traz valiosas contribuições à bibliografia acadêmica.

\section{Palavras-chave}

Terceirização de Transporte; Seleção de Transportador; Decisão Multicriterial. 


\section{Abstract}

Sesto, Rafael Brettas; Leal, José Eugenio (Advisor). The application of simplified AHP method in a massive reduction of carriers, a case of study in Central America. Rio de Janeiro, 2009. 91p. MSc Dissertation (Opção profissional) - Departamento de Engenharia Industrial, Pontifícia Universidade Católica do Rio de Janeiro.

In the last decade it was possible to observe a strong pressure from public opinion to reduce the accidents with environmental consequences and road collisions. Several multinational companies, Non Governmental Organizations, as well as Governments have invested great amount of resources for this aim. Alpha, an oil company, with large operation in Central America, made an enormous carriers reduction in this region, with the objective of being able to manage, in a suitable manner, their contractors and work altogether in the search of accident minimization. Thus, in the lapse of three years the company cancelled its relation with almost one hundred of road transport contractors, and restructured its operation of contracted transport. In order to have only one fraction of the contractors, in relation to what the company had before, a great variety of techniques of analysis for carriers was used. Techniques such as electronic negotiation by Internet, and a multi-criteria decision method developed by the company. Each of these stages was reviewed and compared with the academic bibliography that corresponded. This made possible the comparison of models only written in the bibliography relating their practical application. The results show that the case studied, besides having managed to reach its objective, is a case of success, bringing valuable contributions to the academic bibliography.

\section{Keywords}

Transport outsourcing, carrier selection, multi-criteria decision making. 


\section{Sumário}

1. Introdução 12

1.1. Definição do Problema 12

1.1.1. Definição do processo que será analisado nesse estudo 13

1.2. Objetivo Geral 14

1.3. Objetivos Específicos 15

1.4. Metodologia de trabalho 15

1.5. Estrutura do Trabalho 16

2. Análise situacional da empresa no início da atividade estudada

2.1. Os motivadores da decisão de reduzir o número de transportadores $\quad 20$

2.2. A revisão estratégica do papel da área de aquisições e contratações 22

2.3. A definição das etapas do processo de redução de transportadores 24

3. Definição dos critérios para análise dos transportadores 26

3.1. O processo 26

3.2. Ferramentas de avaliação 27

3.2.1. Análise de saúde financeira e capacidade de investimentos 28

3.2.2. Análise de segurança e operacional 29

4. Definição do número de transportadores a serem contratados em cada país e operação

5. Análise do método de escolha dos transportadores e aplicação da simplificação de Leal (2008) para o método AHP 42

5.1. Requisição de informação para cotação 42

5.1.1. O Algorítmo de geração de valores de oferta 44

5.1.2. A desvantagem de escolher um transportador somente baseado em seu preço 45

5.2. O modelo multicritério de apoio à decisão desenvolvido pela empresa 46

5.3. Métodos multicritério de apoio à decisão 51

5.3.1. Método multicritério de apoio à decisão de escolha de transportador segundo Costa $\quad 52$

5.3.2. Método AHP e simplificação de Leal 54 
6. Conclusão 63

7. Recomendações 64

8. Referências Bibliográficas 65

9. Apêndices 68

9.1. Apêndice 1 - Questionário da avaliação Análise de saúde financeira e capacidade de investimentos. $\quad 68$

9.2. Apêndice 2 - Questionário de Análise de segurança e operacional. 72

9.3. Apêndice 3-Questionário de importância entre os critérios 91 


\section{Lista de figuras}

Figura 1: Formação do custo do combustível em mercados regulados............18

Figura 2: Etapas do desenvolvimento da Função Compras ou

Suprimentos.

Figura 3: Processo típico de Terceirização de Atividades Logísticas

(esquerda) x Processo utilizado pela empresa analisada (direita)....................25

Figura 4: Hierarquia da análise financeira e de segurança..............................28

Figura 5: Hierarquia da análise operacional e de segurança............................31

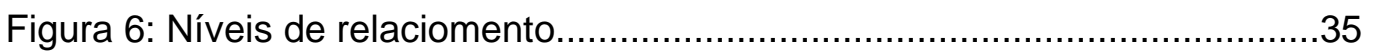

Figura 7: Relação de parceria e o papel do Key Acount Manager......................36

Figura 8: Definição da quantidade de transportadores a serem contratados.....41

Figura 9: Demonstração de um leilão eletrônico reverso..................................43

Figura 10: Hierarquia de simplificada do método AHP....................................45

Figura 11: Matriz-exemplo de comparações paritárias....................................56

Figura 12: Posições transpostas dos valores de uma matriz de comparação. 


\section{Lista de tabelas}

Tabela 1: Exemplo de guia de perguntas de suporte para Avaliação

de Segurança e Operacional

Tabela 2: Exemplificação do algoritmo gerador de valor único para

negociação.

45

Tabela 3: Relação entre a pontuação da análise operacional e de segurança

e as notas derivadas desta análise.

Tabela 4: Relação entre a pontuação da análise de saúde financeira

e capacidade de investimento e as notas derivadas desta análise

Tabela 5: Relação entre a pontuação do leilão eletrônico e as notas

derivadas desta análise. 50

Tabela 6: Resultado do método multicritério de apoio à decisão da Alfa............51

Tabela 7: Representação numérica das comparações paritárias. .......................55

Tabela 8: Resultado da pesquisa de prioridade entre os critérios.......................58

Tabela 9: Matriz comparação dos critérios da pesquisa. ...................................58

Tabela 10: Matriz comparação dos critérios da pesquisa com prioridade...........59

Tabela 11: Priorização quanto ao critério C1 .................................................60

Tabela 12: Priorização quanto ao critério C3 ….............................................61 61

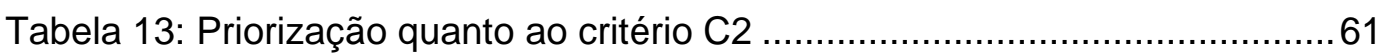

Tabela 14: Resultado final da priorização. .........................................................62 